\title{
A System Model for Water Management
}

\author{
Colin Schenk - Bastien Roquier • Marc Soutter • \\ André Mermoud
}

Received: 31 July 2007/ Accepted: 14 December 2008/Published online: 29 January 2009

(C) Springer Science+Business Media, LLC 2009

\begin{abstract}
Although generally accepted as a necessary step to improve water management and planning, integrated water resources management (IWRM) methodology does not provide a clear definition of what should be integrated. The various water-related issues that IWRM might encompass are well documented in the literature, but they are generally addressed separately. Therefore, water management lacks a holistic, systems-based description, with a special emphasis on the interrelations between issues. This article presents such a system model for water management, including a graphical representation and textual descriptions of the various water issues, their components, and their interactions. This model is seen as an aide-memoire and a generic reference, providing background knowledge helping to elicit actual system definitions, in possible combination with other participatory systems approaches. The applicability of the model is demonstrated through its application to two test case studies.
\end{abstract}

Keywords Integrated water management - Water planning $\cdot$ Water issues $\cdot$ System model $\cdot$ Systems approach $\cdot$ Systems thinking

Water management and planning issues are under intense scrutiny, as shown by the abundant related literature and conferences. Many articles call for a new approach to replace the traditional, sectoral way (Baron and others 2002; Gleick 2003a; Niemczynowicz 2000; Postel 2000). The latter emphasizes for instance that if the 20th century's

C. Schenk $(\varangle) \cdot$ B. Roquier · M. Soutter · A. Mermoud

Ecohydrology Laboratory, Ecole Polytechnique Fédérale de Lausanne, 1015 Lausanne, Switzerland

e-mail: colin.schenk@epfl.ch heavy investments in massive infrastructures (dams, aqueducts, centralized treatments, etc.) brought undeniable benefits to billions of people, it also often came with unexpected social, economical, and environmental costs.

The recommended and now commonly accepted methodology (Carter and others 2005) to address water management and planning is the integrated water resources management (IWRM) approach. In many cases, the implementation of IWRM provided encouraging results, such as in New South Wales (Anderson and Iyaduri 2003), where it allowed identifying opportunities that were not previously apparent, as well as in other Australian states (Mitchell 2006), where reductions in the impact of the development on the water cycle were observed. However, in general, integrated resources management programs' effectiveness is still difficult to assess; frameworks for evaluation seem to be generally lacking (Bellamy and others 2001). Jeffrey and Gearey (2006) also argued that the gap between theory and practice remains extensive and that the benefits of IWRM have not been clearly demonstrated yet.

An important difficulty regarding the implementation of IWRM is the identification of what to integrate. The probably most quoted definition of IWRM, provided by the Global Water Partnership, states: "IWRM is a process which promotes the coordinated development and management of water, land and related resources, in order to maximize the resultant economic and social welfare in an equitable manner without compromising the sustainability of vital ecosystems" (GWP 2000). What does "water, land and related resources" exactly imply? In practice, there are a large number of varying interpretations of what to integrate (Biswas 2004), including various blends of components and concepts such as surface water and groundwater, water supply and demand, various uses, 
different administrative levels, policies, equity, education, health, and so forth (Biswas 2004; Mitchell 2006).

The integration of these components and concepts requires understanding the way they interact as a system. Mitchell (2005) proposed two basic interpretations for this systems approach: (1) comprehensive, implying an exhaustive inventory of the variables and relationships, and (2) integrative, focusing on the identification of key variables and relationships. He mentioned that if the former generally shows the drawback of being very time-consuming, the second one might present the risk of overlooking important elements. In parallel, systems approaches might show features of "hard" or "soft" methods (Stephens and Hess 1999), or blends of both. The former strive toward quantification and objectivity, whereas the latter includes qualitative analysis and tends to capture stakeholders' knowledge through participatory processes.

Recently, a number of promising studies and applications promoted - although they recognize the difficultiesthe inclusion of complex, "soft" aspects (linked with some of the social, environmental, or economic fields) within water or other natural resources management (Bosch and others 2007; Collins and others 2007; Ekasingh and Letcher 2008; Mendoza and Martins 2006; Pahl-Wostl 2007). The major advantages put forward by these methods are the social learning brought by the process and the gain of a deep understanding of the complex problems tackled. However, one of the drawbacks is the time requirement due to the participatory process, especially when water issues are complex, as the latter might involve numerous components, influences, conflicts, and feedback interactions. In this regard, the scientific literature might provide some background help, as it proposes many references about water issues, such as basic and other household needs, industrial, agricultural and energy uses, natural requirements, transportation and recreational purposes, waterrelated risks, management, planning, and governance issues, as well as relations with poverty, health, education, and equity issues (Falkenmark and others 2004; Gleick 2003b; Niemczynowicz 2000; UNDP 2006; UNESCOWWAP 2006; Zehnder and others 2003). However, and although these water-related issues are well documented, they are generally described separately. Therefore, it is difficult to extract the relationships among elements to apprehend the system holistically.

To sum up, the path in IWRM going toward a comprehensive systems approach including "soft" elements can really lead to very rich and interesting insights and robust outputs, but it requires investigation time, for eliciting the components and interactions to be integrated. To facilitate this elicitation process, and therefore reduce the time it necessitates, this article proposes a generic conceptual model for the water management system. The model synthesizes as exhaustively as possible the generic components and interactions involved in water-related issues within a graphical view. It also comes along with an exhaustive review of the water issues, of their related components, and, with special emphasis, of their interrelations. This article also presents two test case studies that demonstrate the applicability and usefulness of the model.

\section{Modeling Methodology}

\section{Inventorying Issues}

In order to scrutinize exhaustively the water management system, the selected methodology consists in a top-down, issues-components approach, starting with the inventory of the water-related issues. This inventory is provided by reviewing the literature.

In this article, issues are to be understood in a general way. They embody different stakeholders' various needs, such as freshwater demand and flood protection, as well as ecosystem requirements. They also include governance and management issues, such as water pricing or stakeholder participation rules. Finally, there are also issues beyond the strict field of water, such as health and tenure rights problems or the state of electric infrastructure.

\section{Inferring the Components}

Although issues are no concrete objects, they correspond to real components that are their physical response. These components generally appear in the literature about water issues; for instance, the "safe water" issue directly relates to the water resource and to some kind of water supply system infrastructure. Therefore, combining literature information and basic analysis provides the inventory of components.

In this article, components are concrete objects, classified into two categories: structural elements (such as surface water, sanitation networks, or dams) and nonstructural elements (like framework for capacity building, water rights, and knowledge database).

\section{Sketching the System Model}

Once components are inventoried, the last step consists in organizing them in a clear and logical way, into the system model. As a very important addition, the relationshipsstructural or functional-must be shown among components during this process. The way to achieve this is a mental exercise of abstraction. The results of such achievements can always be controversial, as there is no unique solution. Different organizations, classifications, 
and generalisations can indeed be imagined, along with different levels of details.

The solution pursued here is a versatile system model. It is meant to enable the addition of further levels of details and possible new components and new relationships.

\section{Water Management System Model}

\section{Graphical Output}

The developed water management system model is shown in Fig. 1, which is described as follows:

- Rectangular blocks are components, which belong to one of the two groups: structural (on the right) or nonstructural (on the left) elements,

- Arrows terminated with a diamond indicate a specialization relation (a relation in which $n$ given objects are subcategories of only one hierarchically upper component),

- Arrows terminated by a triangle indicate a functional relation, whose nature is documented by one or a few keywords and generally by a reference to text descriptions (for instance, A12 refers to point 12 of issue A; text descriptions are given in the next subsection). Arrow-terminated relations might be bidirectional, in which case the keywords for both directions are separated by line symbols (- - ),

- The large gray background rectangle outlines the waterspecific domain. As developed in the next subsection, water-related elements indeed often have connections to elements beyond the strict field of water, such as energy or poverty issues.

\section{Content Overview}

The system model shows a relatively dense components and interrelations network, with no particular reading order. In fact, any point is a possible reading entry point, from which it is possible to navigate, following the interrelations. This is further developed in the section regarding the uses of the model through the example of a hydropower plant. To understand the model in its whole, seven main water issues are hereafter used as perspectives:
A. Safe water and sanitation
B. Water for agriculture and other food production activities
C. Water for industry, energy, and transport
D. Water for recreational, amenity, and spiritual purposes
E. Aquatic ecosystems: benefits and pressures
F. Water-related events and hazards

\section{G. Managing and sharing water}

In these sections, the coded annotations (such as B2 or G9) refer to the interrelations of the model (Fig. 1).

\section{Safe Water and Sanitation}

Access to freshwater is required for people, their households, and the public buildings. It is necessary for consumption and hygiene purposes, in relevant quantities and qualities. Access to safe basic sanitation is also necessary for people, as a fundamental hygienic, privacy, and convenience need.

This issue has obvious impacts on the human health (A1), which, in turn, influences the poverty (A2) issue (for instance, through missed days of work). It is also a factor of inequalities, including between genders (A3), when women and girls are in charge of collecting water from distant sources for instance. Sick children and busy girls cannot attend school and, therefore, this issue also has indirect repercussions on education (A4).

Improving access to water and sanitation might in some cases be achieved through indirect measures. When people do not feel confident enough or lack the funds for investing into infrastructures for their household (such as in slums, where houses have no legitimacy), acting on tenure rights (A5) or providing microcredits, for instance (A6), might prove efficient.

Regarding the legal framework, there are general issues, such as the way institutions are organized, including centralization or decentralization trends, that obviously influence the efficiency in the way infrastructures are managed (A7). People might sometimes be directly involved in projects realization, through construction and maintenance of facilities (A9). Some policies, such as standards (for instance, regarding water quality), also play important roles [e.g., for health protection (A8)].

Safe water and sanitation infrastructures are, of course, strongly linked to the water resource, withdrawing it, pouring it back, and modifying its quality (A10). They deliver water to and retrieve (and treat) wastewater from different consumers, including private and public buildings, swimming pools, and so forth, and provide watering to gardens, sport fields, and so forth (A12). This possibly also involves storage infrastructures (A11).

\section{Water for Agriculture and Other Food Production Activities}

To produce food, agriculture needs water. Agricultural productivity (including also nonalimentary production) might particularly be enhanced by irrigation facilities. However, irrigation accounts for about $70 \%$ of human 


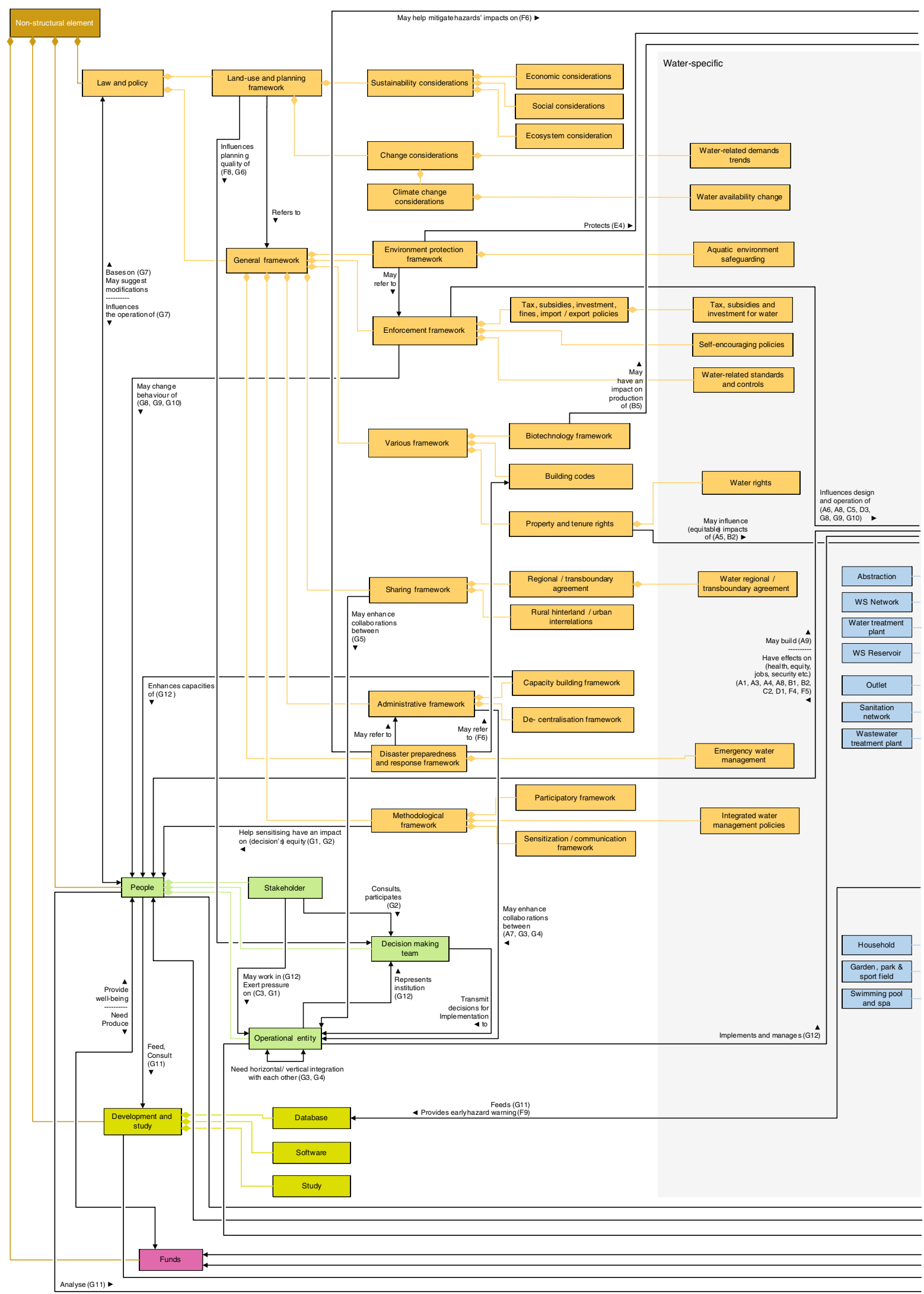

Fig. 1 System model for water management 


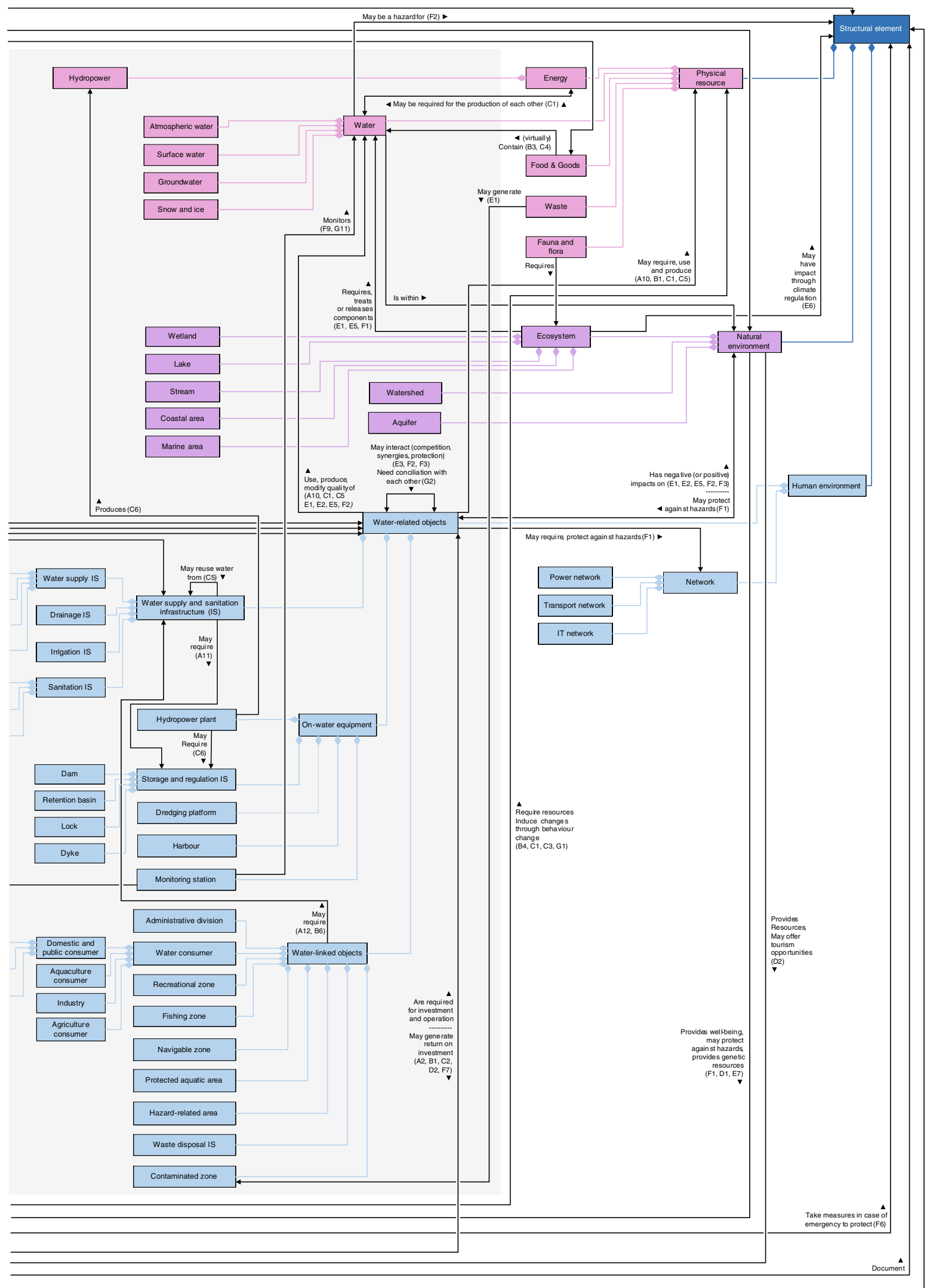

Fig. 1 continued 
water use (IFAD 2006). Aquaculture and capture fishing require water as well, with sufficient quantity and quality. Whereas infrastructure is thus used to supply water, waterlogged areas might conversely benefit from drainage equipment (B6).

This issue is interrelated with people's health through the occurrence of hunger. As for other health problems, hunger further fosters poverty. Conversely, irrigation or aquaculture facilities might reduce both hunger and poverty in rural areas, directly, through increased food production but also through secured access to water, employment, and increased area attractiveness (B1). However, depending on land and water tenure rights, certain people (e.g., women) might not be allowed to access, maintain, and benefit from these facilities, which could therefore create new disparities. Furthermore, they might foster the occurrence of water-borne diseases (B2).

Producing food through irrigation consumes water. Feeding and taking care of livestock further requires water. This leads to the concept of virtual water: producing 1 kilo of cereals or beef requires a certain amount of watermuch more in the latter case. Where water is scarce, importing food with high virtual water content might be an alternative to local production (B3). This also means that food consumption patterns have an influence on water consumption; for instance, eating less meat would mean a diminution of its production and therefore less water consumed (B4).

Impacts on water consumption in food production might also be induced very indirectly. Although this is controversial, biotechnologies might lead to changes-for instance, through the possible finding of organisms resilient to water scarcity (B5).

\section{Water for Industry, Energy, and Transport}

Industries need water for product or services generation. It uses this resource in very different ways, such as for a constituent part of the product (like beverages), for cleaning, for cooling, to generate steam, and so forth [virtual water content of produced goods (C4)]. For transport activities, the need for water is different: The waterways, depending on their geographic features, might enable ships' circulation.

Water is thus also required to produce energy, as a cooling agent or for turbine motion in the case of hydropower plants. The latter might further require additional infrastructures, including dams, in the case of large-scale production (C6). Conversely, energy is required by water infrastructures-for instance, to provide freshwater (pumping stations), to treat wastewater, or to operate devices like dishwashers. Therefore, saving energy might enable water savings and vice versa. This also involves possible savings both ways at the consumers' level (C1). Consumers might also influence water use-and more generally companies' behavior relative to the environment-through the exertion of pressures (e.g., purchasing eco-products) for environmentally friendly practices (C3).

Industries provide employment and generate production. For the operation, they require both water and energy. Therefore, water has an indirect positive influence against poverty. Furthermore, access to reliable electricity provides other opportunities such as powering irrigation systems or enabling activities requiring light after dusk (C2).

Regarding water consumption, reusing wastewater (after a possible treatment) in industries (as well as for irrigation or domestic purposes) offers a technical possibility to save water (but it might require energy). Such measures might be fostered or discouraged by the enforcement framework regulating them directly (reuse standards) or indirectly (water price, subsides, general standards) (C5).

\section{Water for Recreational, Amenity, and Spiritual Purposes}

Watering sport fields and parks, feeding fountains, swimming pools, and spas, providing bathing, sport fishing, navigation, sightseeing, and other water-related activities opportunities - these are all uses of water that might play an important social role, providing well-being (D1). Additionally, possibly multipurpose objects might provide entertainment opportunities; for instance, dams might provide people with a lake area, for instance for bathing, fishing, or windsurfing. All of these aspects of water might also be of economic importance through tourism activities (D2).

Regarding enforcement policies, standards are especially important. They might protect human health through the identification of safe recreational areas, such as beaches showing proper water quality for bathing (D3).

\section{Aquatic Ecosystems: Benefits and Pressures}

Aquatic ecosystems are required by animal and vegetarian species as habitats. They provide goods and services, needed for socioeconomic activities, and they might play a role in risk protection. Conversely, the anthropogenic activities put aquatic ecosystems under pressure, sometimes endangering or even destroying them, along with their animal and vegetarian populations and thus also along with their goods and services.

Anthropogenic pressures on the aquatic ecosystems are of different types: increased sediment loads, pollutions, flow fragmentation (e.g., dams or locks), invasive species, overuse, and so forth. Pollutions might occur from point sources (e.g., accidental spills, wastewater outlets) or from diffuse sources (e.g., agricultural fertilizers, soils contaminated by domestic or industrial wastes) (E1). However, certain 
infrastructures or works might also have positive effects, such as wastewater treatment plants or bank vegetation rehabilitation activities (E2). Moreover, these pressures might also apply to other users, other infrastructures downstream, or those sharing a common water resource; for instance, sediments loads upstream might cause damages or wear to extraction pumps downstream (E3).

Regarding legislation, aquatic ecosystem protection depends on a wide range of policies and standards, at international, regional, and local levels. It also depends on the way these texts are enforced (E4).

Ecosystems provide a wide range of different benefits. Production aspects are discussed in the subsections discussing issues $\mathrm{B}$ and $\mathrm{C}$, related to food, industry, and energy. Recreational aspects are mentioned in the subsection discussing issue $\mathrm{D}$, focusing on that topic. The following subsection, which discusses issue $\mathrm{F}$, covering the hazards related to water, mentions the role played by ecosystems with that regard. Ecosystems also have degradation or dampening capacities of certain components they are exposed to, such as organic loads or sediments. However, conversely, such components might be naturally present in some ecosystems and therefore be released into water (E5). At more global levels, ecosystems are involved in the important functions of climate regulation (E6) and genetic resources reservoir (E7).

\section{Water-Related Events and Hazards}

Floods, wave surges, droughts, and avalanches are waterrelated events that might endanger human lives and infrastructures. They might therefore trigger further disasters, like technological hazards. Conversely, other disasters, like earthquakes, wars, or windstorms might also trigger water emergencies, such as water-lacking refugees' camps, dam breaks, or distribution network failure. Finally, technological hazards might occur, such as pollutant spills (for instance, cases of oil spills caused by foundering vessels), damaging aquatic ecosystems and possibly other water users (F2).

These events might heavily damage ecosystems. Conversely, flooding events might contribute to the spatial and temporal variability of aquatic ecosystems and, therefore, to their richness. Ecosystems might also play an important protection role against hazards (for instance, mangrove and coral reef might lessen the strength of waves) (F1).

People could be hit by such events immediately, and also afterward, due to possible subsequent critical conditions: lack of access to water, water-borne diseases, and disruptions of support infrastructures such as roads or health equipment (F4). Poor countries and poor people are generally the most vulnerable to such events, which therefore tend to further increase inequalities (F5).
Regarding protection against water-related hazards, infrastructures might provide mitigation measures: dikes, channels, embankments, retention basins, dams, and so forth (F3). Investments in protection might prove beneficial, as it is usually less expensive to invest in protection than to pay for fixing the damages afterward (SudmeierRieux and others 2006) (F7).

On the other hand, nonstructural measures include preparedness, emergency management, and response management. Land-use measures, like provision of hazards maps, might prevent constructions in dangerous areas. Building codes might ensure good resilience of the construction. Capacity building efforts will provide managers with the necessary competencies (F6). Monitoring stations, beyond their useful role of general data provision, might also play an important role by providing early warning information (F9).

Another important aspect regarding the management of water-related events and hazards is the consideration of future changes. In particular, climate change might lead to wetter or drier conditions and, therefore, to different or increased risks $(\mathrm{F} 8)$.

\section{Managing and Sharing Water}

As outlined in the previous sections on the issues, water resources are needed for very different uses, including ecosystems safeguarding. These uses might enter into competition with regard to quantity or quality aspects. Therefore, proper management and sharing are required.

As stated earlier, the present generally recognized approach for water planning and management is the integrated water resources management (IWRM). This integration will occur along different complementary axes:

- People: They might be informed and sensitized about water issues, with possible subsequent involvement and behavior changes. They might be included in the decision process, therefore possibly improving its effectiveness (G1).

- Stakeholders' interests: As water users and related stakeholders might have antagonistic or competitive interests, integrating their views might help to leadg to solutions taking, at best, all stakes into account (G2).

- Sectoral institutions (horizontal operational integration): Where different water issues, such as water supply, wastewater treatment, fishing or aquatic systems protection are managed by different institutions, integrating their possibly conflict interests might lead to globally best solutions (G3).

- Hierarchical levels (vertical operational integration): When local measures are planned, they will be in line 
with higher-level strategies regionally, nationally, and internationally (G4).

- Spatial extent: Watersheds and aquifers-if often not coinciding with political boundaries_might represent natural delimitations for water management, as they gather users of a common resource. Therefore, transboundary agreements might play a role in international integration. Moreover, some considerations, like virtual water (import/export) or migrations, might involve larger scales (G5).

- Time and sustainability: In order to avoid conflicts between present and future users, time dimension will be taken into account. It might mean the application of sustainability criteria, integrating the economic, social, and ecological aspects (G6).

- Legislative framework: Making decisions requires an integrated knowledge of the different legal texts and policies, at all levels (i.e., international, regional, etc.) in order to act concordantly (G7). Then this legislative framework needs to be enforced. This might be based not only on strict controls and standards (G8) but also on economic instruments (water pricing, subsidies, fines policies, etc.) (G9) and on self-encouraging incentives (e.g., publication of results, labeling) (G10).

- Data and knowledge: Integrating various kinds of local data is required to provide an information basis on which make decisions. Furthermore, thanks to access to centralized databases, consulting global knowledge, about successes and failures or best management practices for instance, might help in finding solutions (G11). Additionally, improving local knowledge and local competencies, through "capacity building," is important to promote work outputs of good quality (G12).

\section{Using the Model as a General Reference}

The model, as such, can be used as a reference for a better understanding of the water management system; for instance, it could be used to answer questions such as "While implementing a hydropower plant, what components will undergo repercussions?" This example is illustrated in Fig. 2, which is a detailed look into the system model (Fig. 1), showing some of the most directly involved components related to hydropower and their interrelations.

The hydropower plant (1) might require the implementation of storage components, such as dams (2), unless it is a run-of-river plant. It will produce hydropower, which belongs to the energy group (3). As part of the on-water equipment and of the water-related group, interrelations with other members of these components will be investigated; for instance, upstream users or activities might release sediments that could, in the long term, fill the storage unit or wear the turbines, downstream fishing zones might be heavily disrupted, and so forth (4). As water is used for the production of energy, its quality might be modified (5), with possible subsequent impacts on the ecosystem (6). The effects of the dam on the latter will also be investigated: It could provide benefits to the ecosystem through protection against floods, but a variability decrease might endanger the habitats (6). Of course, this analysis could be further performed along any other connections and could, for instance, involve funds (required for investment), people (they might benefit from recreational aspects of a dam lake, but sport fishing or navigation, or beach activities downstream might suffer from it), operational entities, capacity building and disaster frameworks (availability of specialists able to properly implement and operate the plant, including in emergency cases), methodological frameworks (if not all of the stakeholders are represented through a participatory framework, clashes might occur), and so forth.

This fairly straightforward case-impacts of a hydropower plant-was proposed to illustrate the navigation in the model. However, the latter is designed to help naturally as well within more complex problems, such as "How could the water supply network's performance be improved?" or "How can one solve agricultural water needs shortages?" At that level, as shown with the hydropower example, the model provides a way of scanning conceptually - as exhaustively as possible-the space of interrelations and components involved more or less directly in a given issue, possibly pinpointing less intuitive elements that might play a role in it.

\section{Test Case Studies}

The model has been applied to two case studies: (1) Birmingham, England, which accounts with its surrounding municipalities for almost 5 million inhabitants, and (2) Belo Horizonte, Brazil, which accounts for around 2.5 million inhabitants. In both cases, the objectives were to test the correctness and the relevancy of the water management system model through the following:

- The development of a high-level, holistic, overall system representation

- The derivation from the overall view of some usable and concise thematic views.

\section{Application Steps}

In both cases, the studies were mainly carried out by one person who drove the process. The very first step 


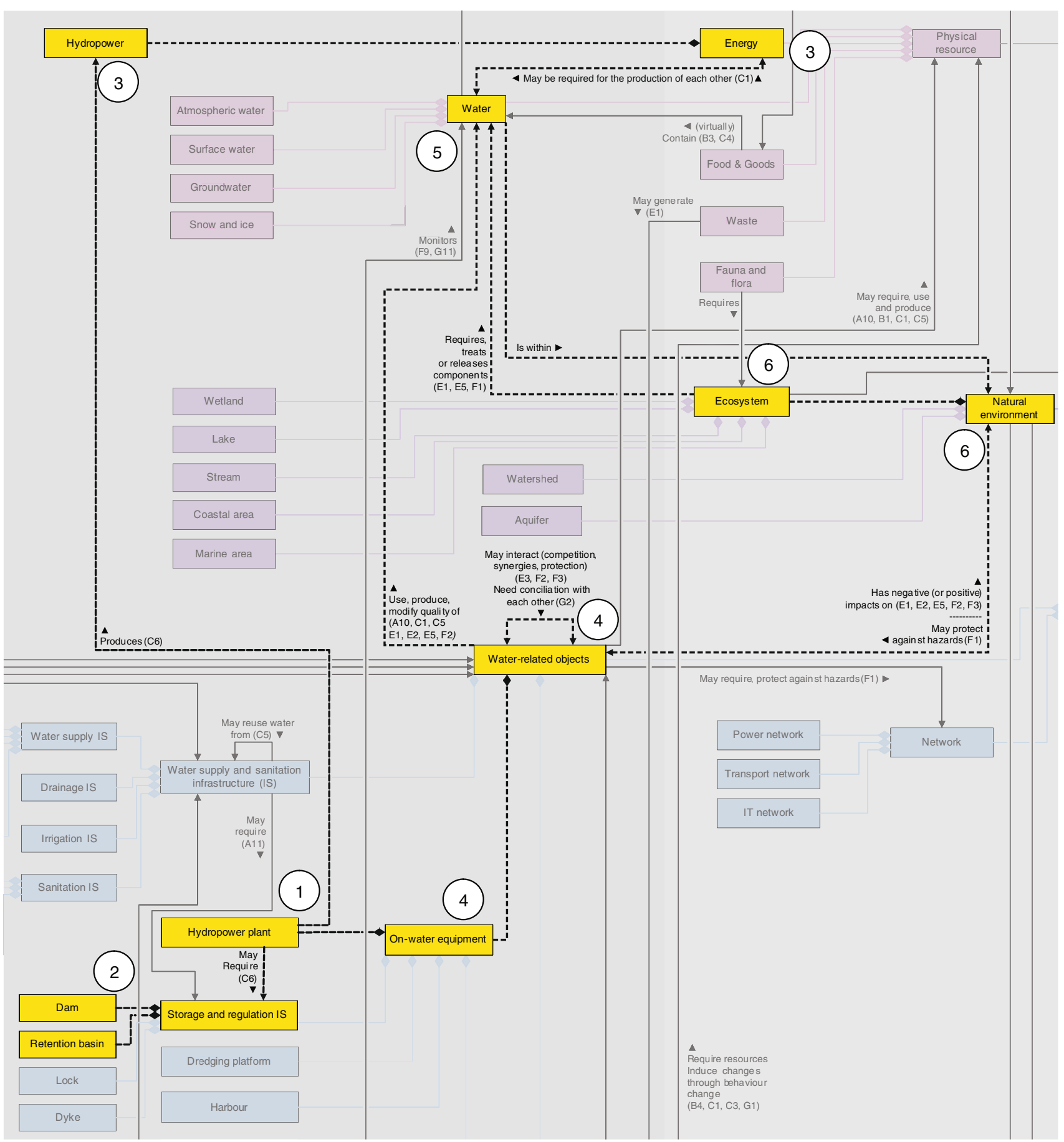

Fig. 2 Components and interrelations of the system model that are closely linked to the hydropower plant element

undertaken by this person was the identification of the stakeholders, through discussions with key people. Then an iterative process started, consisting of a three-step cycle:

1. Analysis of documents and data

2. Implementation of components and interactions

3. Submission of the developments to the stakeholders for discussion.
The analytical and implementation steps made use of the water management system model with the method described earlier: The model was used as a reference to exhaustively inventory the system elements. On that generic basis, real components and interactions were derived. To help manage the thereby created voluminous information mass, components and interactions were introduced 
into a prototype software, which basically allowed storing them-along with some of their features, such as name, icon, or color-in a database and displaying them as diagrams.

The last step was the creation of thematic views, extracting selected information from the overall system network, to provide easier to read, focused views on a few subsystems related to chosen water issues.

Results

In both cases, after an effort of a few months, an overall definition of the water management system has been elicited. In Birmingham, not less than around 700 components and 450 interactions were identified. In Belo Horizonte, around 250 of both were inventoried. The difference can be partially explained by the availability of more information in Birmingham, where a large number of various and detailed studies have been conducted.

Of course, the diagrams showing all these elements are not directly usable as a communication tool. Thematic views were then created to provide readable outputs, focusing on a given topic and therefore showing only the most relevant, linked information extracted from the overall system. Such a thematic view, proposed in Birmingham to illustrate governance issues, is shown in Fig. 3. This view shows, at a very high level, the stakeholders' responsibilities regarding the water as a resource (central components). This is an example of a very global, partial diagram: It was arbitrarily chosen to display only a small number of components and relationships for clarity; the overall systemic view contains indeed much more details vertically (e.g., components, subcomponents, and so forth within the ecosystem or the water-linked infrastructures) and horizontally (e.g., relationships with the laws and policies or with studies). A distinction was made between the influences relationships (light thin connectors) and the money fluxes (darker thick connectors).

The developments of the holistic overall system and of the thematic views provide very rich system-related knowledge base for further developments. They hereby also serve the purpose of demonstrating the applicability of

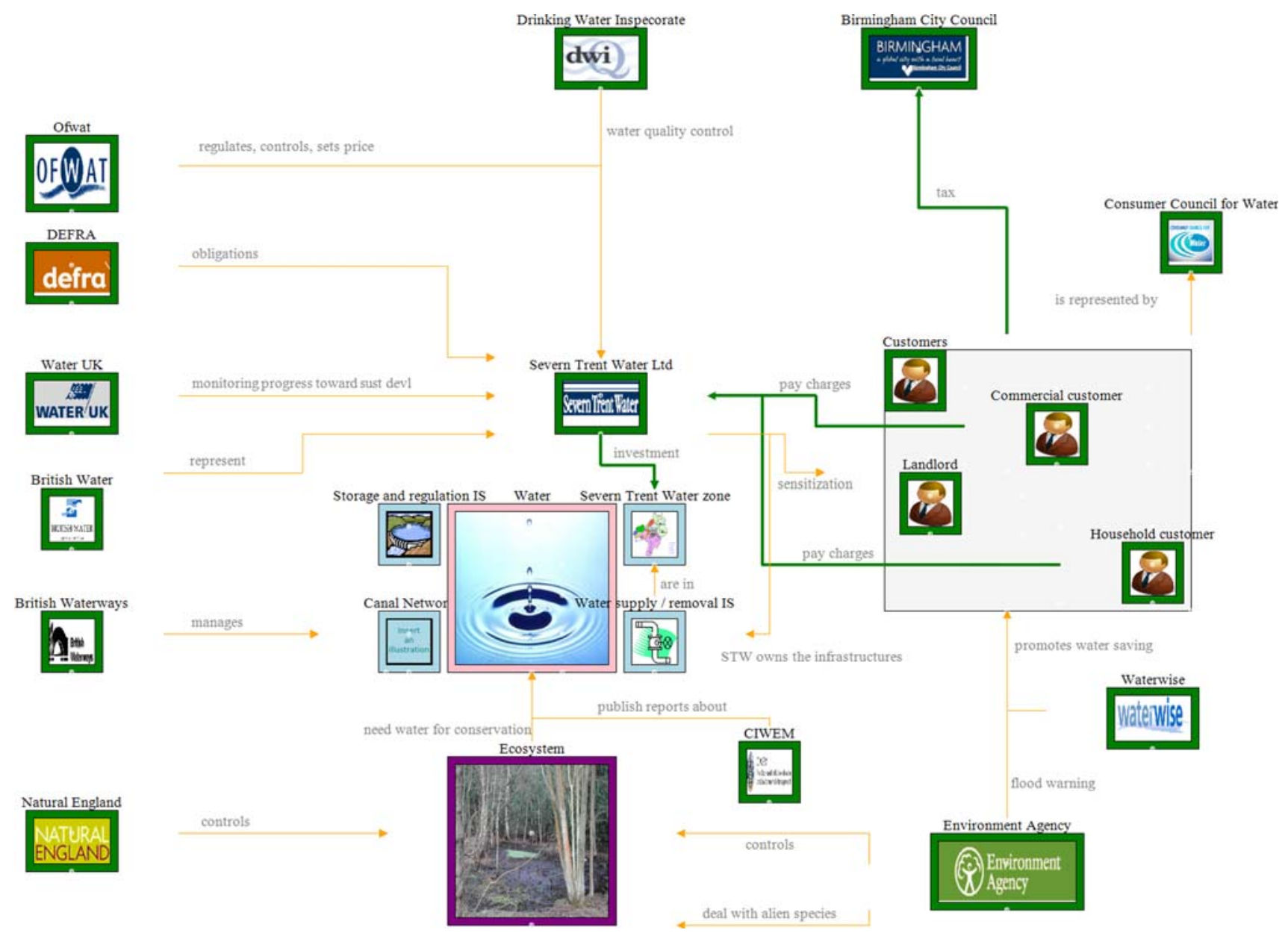

Fig. 3 Thematic view: high-level, partial view over the water governance in Birmingham (currently under the validation process) 
the water management system model as a generic reference.

\section{Discussion}

The overall, holistic water system definition in Birmingham and Belo Horizonte was produced mainly on the basis of one person's leadership, who analyzed the situation, proposed implementations, and submitted them to the stakeholders in an iterative manner. However, more participatory application steps (e.g., through stakeholders' platform meetings) could be followed as well. In that sense, the hereby proposed generic model approach is not mutually exclusive with other systems-based approaches. Rather, it is considered as a tool facilitating the process by providing background knowledge.

There are many methods and tools used in systemsbased approaches used to capture stakeholders' knowledge through participatory approaches; for instance, Bosch and others (2007) presented cases in which stakeholders were involved in systems thinking, using techniques and tools such as influence diagrams construction, blackboard-supported modeling, participatory matrices elaboration, and computer-based modeling. Pahl-Wostl and Hare (2004) applied different techniques in a participatory approach, including mental models building, hexagon modelling, and card sorting to elicit respectively individual representations, system data, and actors' network. Collins and others (2007) applied a systems approach through an iterative process that involved the formulation of systems of interest to take into account the multiple stakeholders' perspectives.

The water management system model, because it proposes a generic structure, might therefore be used within other systems-based approaches applied to water management. In any case, be it a more expert-oriented or a more participatory system elicitation approach, the water management system model might arguably bring important benefits. First, it might reduce the time requirement for the system elicitation process, through the provision of generic background knowledge. This is especially true on longerusage terms: Once a system is described holistically (e.g., in a city), it might act as a reusable source of information. Indeed, thematic views, focusing on any topic of interest, might be extracted from this repository. Additionally, as it strives to be as exhaustive as possible, the model provides an aide-memoire helping to not forget possibly important interrelations. However, one potential consequence of using this feature too tightly could be overlooking possible unusual interactions, not inventoried in the model; therefore, this point should always be considered in the discussion and submission processes with the stakeholders.
Finally, and as mentioned earlier, one of the major advantages of participatory processes is the social learning it brings. If the water management system model is to be used in a more expert-oriented approach, this is an aspect that should be taken into consideration.

Although the water management system model would benefit from further applications at other scales and in contexts other than large cities, the experiences in Birmingham and Belo Horizonte gave encouraging results, with the creation of rich, reusable, and holistic systems definitions, along with some related thematic views.

\section{Conclusion and Perspectives}

In this study, the issues related to water are reviewed as exhaustively as possible, their related components are inferred, and their interrelations are emphasized. This analysis allows subsequent sketching of the elements into a general model for water management. The latter was applied to two test case studies: two large cities. It enabled, as a generic reference, one to derive many components and interrelations, in order to define their overall water system. From this holistic definition, thematic views were proposed, extracting selected information to provide more readable displays, focusing on given topics.

Whereas water-related issues are well known, the analysis into components and interrelations for the realization of a holistic graphical model is an original contribution. This model can be used as an aide-memoire, a generic reference. It can be applied in conjunction with other systems-based, participatory methods or in a very expertoriented manner, allowing reductions of time requirements for systemic analysis. This might be particularly relevant in situations for which an overall system definition is required, because in such cases, the very rich holistic repository of inventoried components and interactions might be reused. In conclusion, this model might help undertaking a comprehensive systems approach, including "soft" system elements, in integrated water management.

Regarding the perspectives, an important aspect emphasized by the test case studies is the need for an advanced tool to help manage the complex and numerous system-related data. This software might not only allow storing and displaying components and interactions but also dealing with related data, such as numeric values, comments, problem notifications, and so forth. It could therefore lead to the realization of an information system dedicated to the management of systems-based data, an "information system on the system." Such an information system might enable the creation of interesting advanced thematic views featuring, for instance, proportional fluxes arrows and problems structures views. 
Acknowledgments This work was financed by the EU within the frame of the SWITCH project (Sustainable Water Improves Tomorrows Cities' Health). The reported study was performed in Theme 1 focusing on the Urban Water Paradigm Shift. It benefited from the invaluable contributions of $\mathrm{Mr}$. Ph. Brandenberg and Mr. J.-J. Dessimoz regarding the model application to the test case studies. Very insightful comments from Dr. Geoff Syme and from other anonymous reviewers were also greatly appreciated.

\section{References}

Anderson J, Iyaduri R (2003) Integrated urban water planning: big picture planning is good for the wallet and the environment. Water Science and Technology 47(7-8):19-23

Baron JS, Poff NL, Angermeier PL et al (2002) Meeting ecological and societal needs for freshwater. Ecological Applications 12(5): $1247-1260$

Bellamy JA, Walker DH, McDonald GT, Syme GJ (2001) A systems approach to the evaluation of natural resource management initiatives. Journal of Environmental Management 63(4):407423

Biswas AK (2004) Integrated water resources management: a reassessment - a water forum contribution. Water International 29(2):248-256

Bosch OJH, King CA, Herbohn JL, Russell IW, Smith CS (2007) Getting the big picture in natural resource management: systems thinking as 'method' for scientists, policy makers and other stakeholders. Systems Research and Behavioral Science 24(2): 217-232

Carter N, Kreutzwiser RD, de Loe RC (2005) Closing the circle: linking land use planning and water management at the local level. Land Use Policy 22(2):115-127

Collins K, Blackmore C, Morris D, Watson D (2007) A systemic approach to managing multiple perspectives and stakeholding in water catchments: some findings from three UK case studies. Environmental Science and Policy 10(6):564-574

Ekasingh B, Letcher RA (2008) Successes and failures to embed socioeconomic dimensions in integrated natural resource management modeling: 1Lessons from Thailand. Mathematics and Computers in Simulation 78(2-3):137-145

Falkenmark M, Gottschalk L, Lundqvist J, Wouters P (2004) Towards integrated catchment management: increasing the dialogue between scientists, policy-makers and stakeholders. International Journal of Water Resources Development 20(3):297-309

Gleick PH (2003a) Global freshwater resources: soft-path solutions for the 21st century. Science 302(5650):1524-1528
Gleick PH (2003b) Water use. Annual Review of Environment and Resources 28:275-314

GWP (2000) Integrated water resources management. Global Water Partnership-Technical Advisory Committee, Stockholm, Sweden

IFAD (2006) Water for food, agriculture and rural livelihoods. In: UNESCO-WWAP (ed) Water, a shared responsibility: The United Nations World Water Development Report 2. United Nations Educational, Scientific and Cultural Organization (UNESCO) and Berghahn Books, Paris, pp 243-274

Jeffrey P, Gearey M (2006) Integrated water resources management: lost on the road from ambition to realisation? Water Science and Technology 53(1):1-8

Mendoza GA, Martins H (2006) Multi-criteria decision analysis in natural resource management: a critical review of methods and new modelling paradigms. Forest Ecology and Management 230(1-3):1-22

Mitchell B (2005) Integrated water resource management, institutional arrangements, and land-use planning. Environment and Planning A 37(8):1335-1352

Mitchell VG (2006) Applying integrated urban water management concepts: a review of Australian experience. Environmental Management 37(5):589-605

Niemczynowicz J (2000) Present challenges in water management: a need to see connections and interactions. Water International 25(1):139-147

Pahl-Wostl C (2007) The implications of complexity for integrated resources management. Environmental Modelling and Software 22(5):561-569

Pahl-Wostl C, Hare M (2004) Processes of social learning in integrated resources management. Journal of Community and Applied Social Psychology 14(3):193-206

Postel SL (2000) Entering an era of water scarcity: the challenges ahead. Ecological Applications 10(4):941-948

Stephens W, Hess T (1999) Systems approaches to water management research. Agricultural Water Management 40(1):3-13

Sudmeier-Rieux K, Masundire H, Rizvi A, Rietbergen S (2006) Ecosystems, livelihoods and disasters: an integrated approach to disaster risk management. IUCN-The World Conservation Union, Cambridge

UNDP (2006) Human development report 2006. Palgrave Macmillan, New York

UNESCO-WWAP (ed.) (2006) Water, a shared responsibility: The United Nations World Water Development Report 2. United Nations Educational, Scientific and Cultural Organization (UNESCO) and Berghahn Books. Paris

Zehnder AJB, Yang H, Schertenleib R (2003) Water issues: the need for action at different levels. Aquatic Sciences 65(1):1-20 